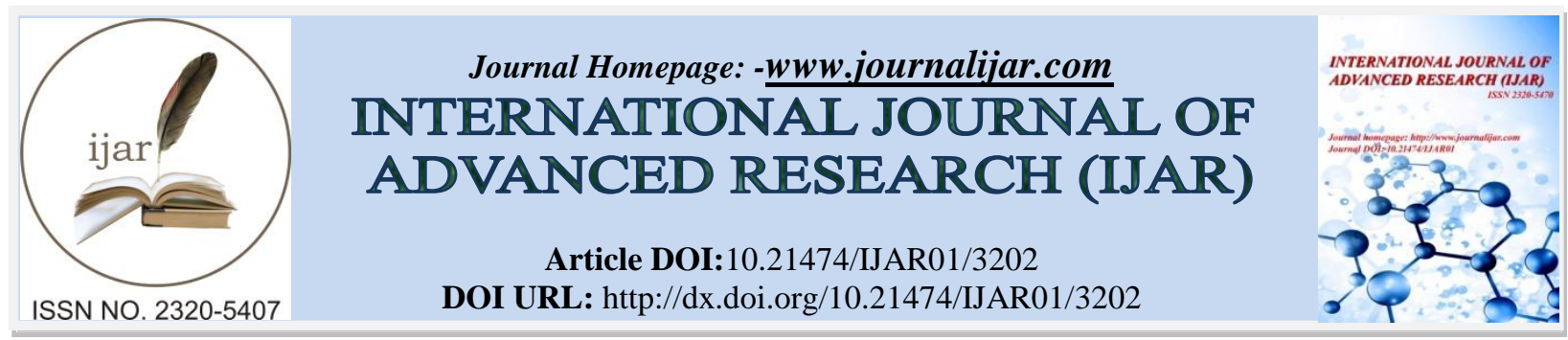

RESEARCH ARTICLE

\title{
AN ANTHROPOMETRIC PROFILE AMONG THE KORAGA TRIBE OF UDUPI DISTRICT, KARNATAKA STATE
}

\section{Ashwini Pujar ${ }^{1}$, Praveen Hoogar ${ }^{1}$ and T.T.Basavanagouda ${ }^{2}$}

1. Research Scholar, Department of Studies in Anthropology, Karnatak University, Dharwad, Karnataka State, India.

2. Professor, Department of Studies in Anthropology, Karnatak University, Dharwad, Director, Karnataka State Tribal Research Institute,Mysore, Karnataka State, India.

\section{Manuscript Info}

[........................

Manuscript History

Received: 23 December 2016

Final Accepted: 10 January 2017

Published: February 2017

Key words:-

Koraga, PVTG, Skinfold Thickness,

MUAC, Nutritional Status,

Anthropometry and Udupi

\section{Abstract}

The present study was carried out to evaluate the Skinfold Thickness, Height for age, Weight for age, BMI, and MUAC of Koraga tribal people representing three taluks of Udupi district, Karnataka State. In Karnataka,Koraga tribes are identified as PVTG. The data or information was recorded through interview schedule and a survey was conducted. Total 500individuals were studied from twenty hamlets in three taluks ofUdupi District. The foregoing study reveals thatamong the total samples $90.8 \%$ (454) of themare suffering from different grades of Chronic Energy Deficiency.

Copy Right, IJAR, 2017, All rights reserved.

\section{Introduction:-}

As per the 2011 census, the tribal population is $8.6 \%$ of the total population. $89.9 \%$ of them reside in rural areas and $10.0 \%$ in urban areas. Whereas in Karnataka, as per 2011 census thetotal tribal population is $6.95 \%$ of the total population with $19.27 \%$ of them residing in urban and rest of $80.72 \%$ of the peoples are found in rural parts. Few studies in India provide detailed descriptions of the tribal community. Good nutrition is a basic element of health. A healthy person leads thenation in abettermanner. Most of the tribal people of India have their own geographically isolated lifestyle. Inadequate food habits along with traditional socio-cultural and biological activities may lead to a high proportion of child undernutrition (Balgir et al. 2002; Rao et al. 2006). Most of the tribal people are exposure to different kinds of diseases and suffering from malnutrition. Good nutrition of the people is avital component of healthy life. The Indian tribal people are deprived economically.

Tribal peoples are recognized to avery close relationship with the ecology and the environment because of their fulfillment of daily nutritional requirements with food foraged from nature. They are dependent on the forest. But after the forest act tribal are not allowed to collect forest produces due to this reason tribal are not getting any nutritional supplements. The government has providing nutritional supplements to the tribes, but most of them are not aware of the food and they are not using. This leads to malnutrition. Inadequacies in nutritional intake or undernutrition can be considered a major source of many adverse effects on the growth and health of individuals (Gordon et al., 1968).

Most of the tribal community in India is addicted to alcohol consumption and they don't care about their health. They have their strong traditional beliefs and practices of healing the diseases. They have their own ethno 
medicines.Still, most of them are practicing their own tradition to heal of the disease. The present study shows the anthropometric description of the tribal people to know their nutritional status.

Anthropometry is a key component to assess the nutritional status. This is the study of measurements and proportion of the human body using different anthropometric instruments. MUAC is the circumference of the left upper arm, measured at the mid-point between the tip of the shoulder and the tip of the elbow (Olecranon process and the Acromium).

\section{Material and Method:-}

For the present study a total of 500 subjects which 243 male, 257 female were selected during the study. Fieldwork was conducted during the month of March to August. The Data were gathered from different hamlets of Koraga tribes in three taluks of Udupi District. Anthropometric measurements were taken using thestandard procedure. The anthropometric measurements (Height, Weight, Mid Upper Arm Circumference and Skinfold Thickness at Triceps) of Koraga tribal people were recorded using techniques given by Jelliffe (1966). The height was measured with the help of Anthropometric rod, weight was measured with the help of adigitalweighing machine and it was measured to the nearest 0.1 kilogram., MUAC was measured with the aid of tape to the nearest $0.1 \mathrm{~cm}$. and skinfold thickness was measured to the nearest 0.1 millimeterswith the help of futubaskin fold calliper.

BMI was computed using the following standard equation:-

BMI = weight (in $\mathrm{Kg}$ )/ (height) ${ }^{2}$ (in meters). Nutritional status was evaluated using internationally accepted BMI guidelines (WHO 1990: 854). The following cut-off points were used: CED BMI <18.5, normal: BMI= 18.5-25.0, overweight: $\mathrm{BMI} \geq 25.0-30-0$ and above (PujarA et.al., 2016).

The data was analysed with the use of Statistical Package for Social Science 22.0 Version software.

\section{Koraga Tribe:-}

In Karnataka,totally 50 tribes are scheduled under the list of Schedule Tribes. Among them, two tribes are identified as Particularly Vulnerable Tribal Groups (PVTG, earlier it called as PTG-Primitive Tribal Groups)who has alow level of literacy rate, thepre-agricultural level of technology and decliningpopulation.Koragais one among them. Most of the Koraga population resides in coastal regions of Karnataka that is Dakshina Kannada and Udupi district. According to the 2011 census, their population in these two districts is 14,794. As the census of India, Koraga tribal population is drastically declining over the period of time. They are skillful in making baskets using creepers (Beelu), canes, and bamboos by splitting and weaving them artistically. Basketry is the main source of income of Koraga tribal community. But thenowadays majority of them working as daily wage laborers in panchayat, municipality, hotels, and hostels etc. Physically they are very quiet and inoffensive race, small and slight, the men seldom exceeding five feet six inches, black skinned, thick-lipped, noses broad and flat, high chick bones and sloping foreheads and with wavy dark rough hairs and very distinct eyes and lips. They speak Koraga language, which is the mixture of Tulu and Kannada, but while communicating with others they speak the Kannada language. In three taluks of Udupi district, Koraga tribes speak adifferent dialect. These taluk people culture, tradition is also differed each other.

\section{Results and Discussion:-}

A total of five hundred individual's height, weight, MUAC and skinfold thickness at triceps were recorded with the help of anthropometric instruments. A total 500 individuals comprising $48.6 \%$ males and $51.4 \%$ were females (Table 1, Fig: 1).

Table no. 2 (Fig:2) shows that maximum number of individuals 36.4\% (182) were suffering from CED GradeII(16.0-17.0) type of malnutrition following 34.8\% (174) respondentswere suffering from Grade-III $(<16.0)$ type of malnutrition and 19.6\% subjects were suffering from Grade-I (17.0-18.5) type of malnutrition. Totally, out of 500 respondents, 454 subjects were suffering from different grades of Chronic Energy Deficiency.

In the 4-6 years age group there was aslight difference in the mean height of males $(97.5 \pm 11.38)$ and females (96.1. \pm 13.4$)$. In the 7-18 years age group also, there was no much difference in the mean height of males and females. 19-60+ years of age group there was a huge difference in mean height found.In the age group of 4-15years of age group, there was slight differences in weight of male and females, whereas above 16 years upto 60+ age 
group female were shorter by about 6-7 $\mathrm{kg}$ lighter as compared to themale of the same age group. The tribal peoples were shorter and lighter when compared with the NCHS and ICMR standards(Table No-3, Fig-3).

In the 7-9 years age group there was much difference in the mean MUAC of male (14.80 \pm 2.34$)$ and females (18.39 \pm 14.2$)$.In the age group of 13-15 years,there was also much difference in the mean mid-upper arm circumferencesin males $(17.6 \pm 2.76)$ and females $(22.0 \pm 2.93)$.In remaining age group there $1-2 \mathrm{~cm}$ differences found between male and females.In the 10-12 years age group there was much difference in the mean Triceps skinfold thickness of male $(9.38 \pm 2.66)$ and females $(7.79 \pm 2.86)$. In remaining age group, there were $1 \mathrm{~mm}$ differences found between male and females (Table No-4, Fig-4).

Table 1:- Gender wise distribution of the sample

\begin{tabular}{|c|c|c|}
\hline Gender & Frequency & Percent \\
\hline Male & 243 & 48.6 \\
\hline Female & 257 & 51.4 \\
\hline Total & 500 & 100 \\
\hline
\end{tabular}

\section{Gender wise Distribution of collected samples}
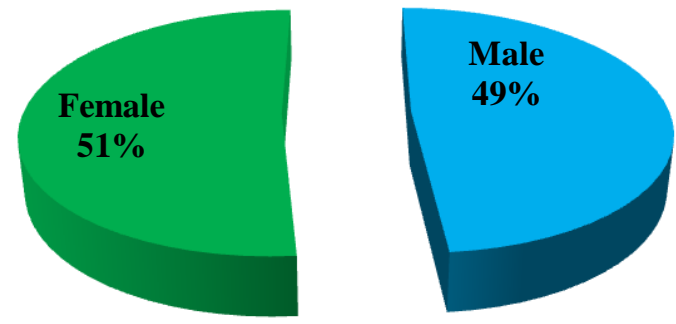

Fig 1:- Gender wise distribution of the collected sample

Table 2:- Distribution of BMI according to gender

\begin{tabular}{|c|c|c|c|c|c|c|}
\hline BMI Grades & Male & $\mathbf{\%}$ & Female & \% & Total & \% \\
\hline CED III (<16.0) & 82 & 33.7 & 92 & 37.8 & 174 & 34.8 \\
\hline CED II (16.0-17.0) & 93 & 38.2 & 89 & 36.6 & 182 & 36.4 \\
\hline CED I (17.0-18.5) & 52 & 21.3 & 46 & 18.9 & 98 & 19.6 \\
\hline Low weight normal (18.5-20.0) & 09 & 3.70 & 19 & 7.81 & 28 & 5.6 \\
\hline Normal (20.0-25.0) & 05 & 2.05 & 09 & 3.70 & 14 & 2.8 \\
\hline Obese (25.0-30.0+) & 02 & 0.82 & 02 & 0.82 & 04 & 0.8 \\
\hline Total & $\mathbf{2 4 3}$ & $\mathbf{4 8 . 6}$ & $\mathbf{2 5 7}$ & $\mathbf{5 1 . 4}$ & $\mathbf{5 0 0}$ & $\mathbf{1 0 0}$ \\
\hline
\end{tabular}




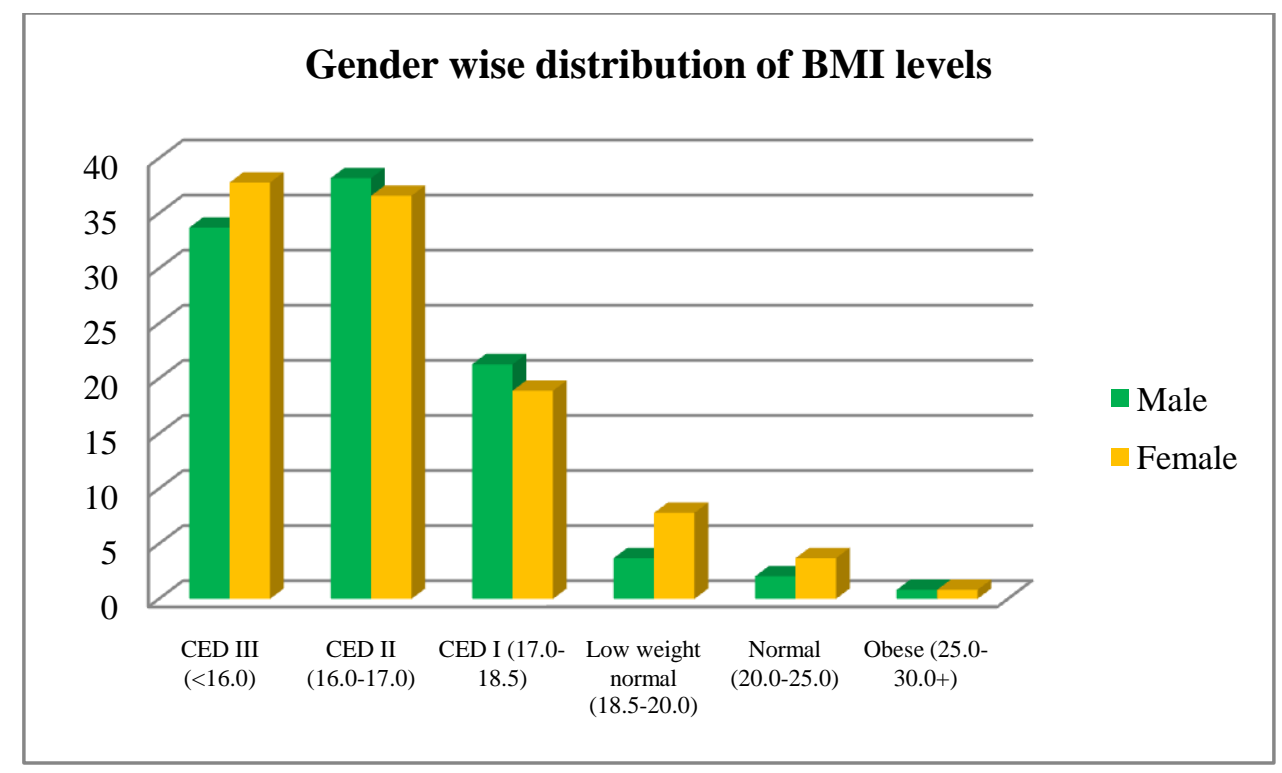

Fig 2:- Gender wise distribution of BMI levels

Table 3:- Distribution of Height $(\mathrm{cm})$ and Weight $(\mathrm{kg})$ of Koraga tribes according to age and gender

\begin{tabular}{|c|c|c|c|c|c|c|c|c|}
\hline \multirow{3}{*}{$\begin{array}{c}\text { Age } \\
\text { Group }\end{array}$} & \multicolumn{4}{|c|}{ Height $(\mathbf{c m})$} & \multicolumn{4}{|c|}{ Weight (kg) } \\
\hline & \multicolumn{2}{|c|}{ Male } & \multicolumn{2}{|c|}{ Female } & \multicolumn{2}{|c|}{ Male } & \multicolumn{2}{|c|}{ Female } \\
\hline & Mean & SD & Mean & SD & Mean & SD & Mean & SD \\
\hline $4-6$ & 97.50 & 11.387 & 96.18 & 13.415 & 12.36 & 2.37 & 11.27 & 2.19 \\
\hline $7-9$ & 112.60 & 5.739 & 111.50 & 8.726 & 17.00 & 2.66 & 15.67 & 3.71 \\
\hline $10-12$ & 126.50 & 6.761 & 132.29 & 11.612 & 22.13 & 3.94 & 23.00 & 6.07 \\
\hline $13-15$ & 141.20 & 15.631 & 138.09 & 14.321 & 31.00 & 8.66 & 30.18 & 10.05 \\
\hline $16-18$ & 153.77 & 9.175 & 150.10 & 6.688 & 39.96 & 8.37 & 40.60 & 8.61 \\
\hline $19-24$ & 162.88 & 8.467 & 150.00 & 5.451 & 48.59 & 7.22 & 42.52 & 9.19 \\
\hline $25-30$ & 161.39 & 6.609 & 151.24 & 5.122 & 49.36 & 6.24 & 42.69 & 7.83 \\
\hline $31-40$ & 160.52 & 7.525 & 150.97 & 5.015 & 49.32 & 9.21 & 44.80 & 9.34 \\
\hline $41-50$ & 159.23 & 7.727 & 148.69 & 5.058 & 50.33 & 10.09 & 44.07 & 7.36 \\
\hline $51-60$ & 156.70 & 4.296 & 148.39 & 5.903 & 51.80 & 10.05 & 42.56 & 6.39 \\
\hline $60+$ & 161.05 & 8.416 & 147.28 & 5.245 & 47.11 & 10.33 & 41.67 & 9.27 \\
\hline
\end{tabular}

Table 4:- Distribution of MUAC (cm) and Triceps $(\mathrm{mm})$ of Koraga tribes according to age and gender

\begin{tabular}{|c|c|c|c|c|c|c|c|c|}
\hline \multirow{2}{*}{$\begin{array}{c}\text { Age } \\
\text { Group }\end{array}$} & \multicolumn{4}{|c|}{ MUAC (cm) } & \multicolumn{3}{c|}{ Mriceps (mm) } \\
\cline { 2 - 9 } & \multicolumn{3}{|c|}{ Male } & \multicolumn{2}{c|}{ Female } & \multicolumn{3}{c|}{ Memale } \\
\cline { 2 - 9 } & Mean & SD & Mean & SD & Mean & SD & Mean & SD \\
\hline $4-6$ & 14.46 & 1.19 & 13.91 & .944 & 4.36 & 1.64 & 4.73 & 2.41 \\
\hline $7-9$ & 14.80 & 2.34 & 18.39 & 14.2 & 5.90 & 1.59 & 6.11 & 3.23 \\
\hline $10-12$ & 17.13 & 1.45 & 19.50 & 3.32 & 9.38 & 2.66 & 7.79 & 2.86 \\
\hline $13-15$ & 17.67 & 2.76 & 22.00 & 2.93 & 10.80 & 3.59 & 11.36 & 4.00 \\
\hline $16-18$ & 21.73 & 2.69 & 21.55 & 4.09 & 9.54 & 2.67 & 9.70 & 2.77 \\
\hline $19-24$ & 24.09 & 11.2 & 22.31 & 3.65 & 8.56 & 3.60 & 10.03 & 3.68 \\
\hline $25-30$ & 23.45 & 1.75 & 24.14 & 2.88 & 9.03 & 2.58 & 9.59 & 3.56 \\
\hline $31-40$ & 22.89 & 3.47 & 24.62 & 8.21 & 8.00 & 3.14 & 9.22 & 2.91 \\
\hline $41-50$ & 23.13 & 2.41 & 22.97 & 3.66 & 9.37 & 2.76 & 10.00 & 3.78 \\
\hline $51-60$ & 23.20 & 2.15 & 22.72 & 2.82 & 8.10 & 4.17 & 8.72 & 4.90 \\
\hline $60+$ & 21.32 & 3.03 & 21.78 & 4.16 & 7.58 & 3.11 & 6.28 & 2.02 \\
\hline
\end{tabular}




\section{Conclusion:-}

Healthcare is one of the most important of all human endeavours to improve the quality of life especially of the tribal people (Balgir, 1995, 2000, 2005 \& 2007). Health problems and health practices of tribal communities have been profoundly influenced by the inter- play of complex social, cultural, educational, economic and political practices (Balgir 2005). Most of the tribal population in India suffering from malnutrition because their general customs, traditions, values, beliefs and practices associated with their health and disease and it has been closely related to the treatment of diseases. In most tribal communities, there is a wealth of folklore associated with health belief and tribal people are mainly depend upon the forest products after the forest act (2006) implemented tribal are restricted to enter in to the forest and this is one of the important factor that tribal are suffering from malnutrition.

In Karnataka Koraga tribehas identified as Particularly Vulnerable Tribal Groups (PVTG). The present study reveals that the only $8.4 \%$ and $0.8 \%$ are respectively falling in normal and obese categories remaining all are suffering from different grades of malnutrition. This is also a prime reason for community stagnancy or decline in population. The finding reveals precautionary actions are desirable to progress the health and nutritional condition of the Koraga tribe in the state.

\section{Acknowledgement:-}

Authors acknowledge the whole community for their cooperation and constant support during the research work.

\section{References:-}

1. Aiyappan A (1948) 'Report on the Socio- economic Condition of the Aboriginal tribes of the Province of Madras'. Madras: Government Press.

2. Balgir RS, Kerkatta AS, Murmu B, Dash BP (2002) 'Clinical assessment of health and nutritional status of Gond children in Kalahandi district of Orissa'.Ind J Nutr Diet, 39(1): 31-37.

3. Balgir RS (1995) 'Genetic markers in the tribal health, development, and welfare with special reference to North Eastern India. In: Anthropology, Population and Development' Sharma JC.(Ed.) New Delhi: Inter-India Pub, 151-171.

4. Jelliffe DB (1966) 'The Assessment of the Nutritional Status of the Community', WHO Monogr Sec No53, Geneva: World Health Organization.

5. Subal Das, Kaushik Bose (2012) 'Nutritional deprivation among Indian tribals: A cause for concern'Anthropological Notebooks, XVIII/2.

6. National Center for Health Statistics 1976. NCHS Growth Curves for Children 0-18 years. The United States, DHEW Publication, No. (PHS) Series 11 (165) 78-1650, Rockville, MD, 22-39.

7. Pujar A, Hoogar P and Basavanagouda TT (2016) 'An Assessment of Nutritional Status among Jenukuruba Tribe of Kodagu District', Journal of Community Medicine \& Health Education, Volume-6, Issue-5. 